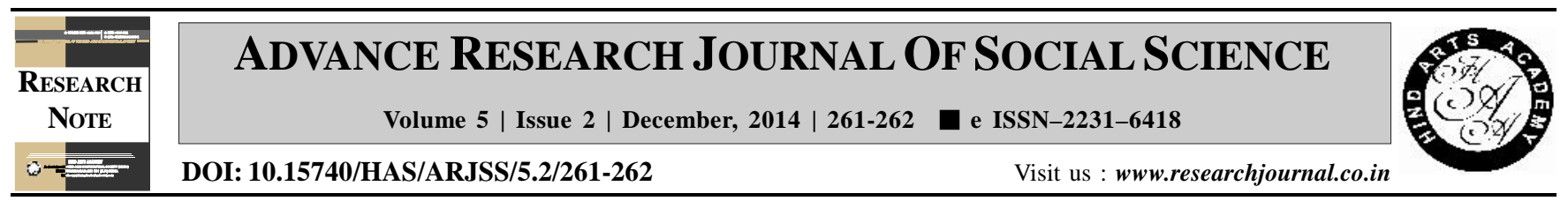

\title{
Impact of farm school: A study of Khowai district of Tripura
}

Dipak Nath* and Dipankar Dey

Krishi Vigyan Kendra, KHOWAI (TRIPURA) INDIA

(Email: spd020@yahoo.co.in)

\section{ARTICLE INFO :}

Received : 07.11 .2014

Accepted : $\quad 30.11 .2014$

\section{KEY WORDS :}

Farm School, IPM

\section{HOW TO CITE THIS ARTICLE :}

Nath, Dipak and Dey, Dipankar (2014). Impact of farm school: A study of Khowai district of Tripura. Adv. Res. J. Soc. Sci., 5 (2) : 261-262.

*Author for correspondence

\begin{abstract}
Farm School (FS) on IPM in vegetables was conducted in Kamalnagar village of Khowai district of Khowai with 30 progressive farmers of the village. The study was conducted just after completion of the FS with 60 respondents (30 participants and 30 non participant farmers) to find the knowledge level on IPM technology. The socio personal characteristics like age, educational level and mass media exposure of the respondents were also studied. The study revealed that majority $(70.00 \%)$ of the participant farmer had medium level of knowledge followed by 26.67 per cent and 3.33 per cent had high and low level of knowledge on IPM technology, respectively, while in case of non participant farmer majority $(86.67 \%)$ of the respondents had low level of knowledge followed by 13.33 per cent medium and no one had high level of knowledge.
\end{abstract}

